\title{
Achieving Horizontal Equity: Must We Have a Single-Payer Health System?
}

\author{
Michael K. Gusmano \\ State University of New York, Downstate Medical Center \\ Daniel Weisz \\ International Longevity Center-USA \\ Victor G. Rodwin \\ New York University
}

\begin{abstract}
The question posed in this article is whether single-payer health care systems are more likely to provide equal treatment for equal need (horizontal equity) than are multipayer systems. To address this question, we compare access to primary and specialty health care services across selected neighborhoods, grouped by average household income, in a single-payer system (the English NHS), a multiple-payer system with universal coverage (French National Health Insurance), and the U.S. multiple-payer system characterized by large gaps in health insurance coverage. We find that Paris residents, including those with low incomes, have better access to health care than their counterparts in Inner London and Manhattan. This finding casts doubt on the notion that the number of payers influences the capacity of a health care system to provide equitable access to its residents. The lesson is to worry less about the number of payers and more about the system's ability to assure access to primary and specialty care services.
\end{abstract}

\section{Equity in Three Contrasting Health Systems}

The U.S. health care system presents a stark contrast to France and England, both of which provide universal health care coverage, albeit in different ways. France is an example of statutory national health insurance (NHI) systems that rely on significant mandatory payroll taxation, much like Social Security in the United States. It has multiple health insurance funds, but unlike the multipayer system in the United States, French health insurance funds all operate within a common framework in which no one is permitted to opt out of the system, health insurance funds are not 
allowed to compete by lowering premiums, and all funds use the same reimbursement scheme. England is the prototype model of a national health service (NHS) that relies largely on general revenue taxation and spends considerably less on health care as a share of gross domestic product (GDP) (8.1 percent) than France (10.5 percent) or the United States (15.3 percent).

The three countries also vary significantly in the organization of their health care systems. In England, fewer than 5 percent of hospital beds are in private institutions. In France, although public hospitals are dominant, there is still a significant role for private institutions. Moreover, most French physicians in ambulatory care - general practitioners as well as specialists - work in fee-for-service private practice, as in the United States. In contrast, primary care trusts provide almost all primary care in England through a mixed reimbursement system for general practitioners.

In both France and England, unlike the United States, there are strong institutional barriers between salaried physicians in public hospitals and those working in private community-based practice. In France, some general practitioners (GPs) as well as specialists in private practice have stronger ties to public hospitals and collaborate formally with private hospitals more often than in England, whose health system is characterized by poor linkages between the hospital and ambulatory-care systems. The absence of strong linkages between the hospital and ambulatory care system, coupled with the role of GPs as gatekeepers, may limit access to specialty care in England. On the other hand, the absence of gatekeepers and direct access to specialists in the French health care system could lead to a lack of coordination and overuse of specialty care services (Macinko, Starfield, and Shi 2003). Although it is possible that the French are receiving too many specialty services, our findings for Paris suggest that the lack of formal mechanisms for care coordination is not resulting in high rates of avoidable hospitalization.

As in France, and in contrast to the United States, England has minimal financial barriers to primary care and a strong commitment to the principle of horizontal equity. The English NHS was established to "generalize the best," in Aneurin Bevan's memorable slogan, and to provide health services free at the point of use, "from each according to their means to each according to their needs" (Oliver 2008). In comparison to France and the United States (for those who are well insured), England has tighter access barriers to specialty services. Nonetheless, France and England have both succeeded in eliminating financial barriers to health 
care access. For this reason alone, it is reasonable to expect that access to care in these systems will be more equitable than the United States.

A host of studies, including one that examined health care access in Winnipeg, Ontario (Roos and Mustard 1997), have concluded that Organisation for Economic Co-operation and Development (OECD) nations with universal (or near-universal) access have an equitable distribution of primary care visits across income groups (van Doorslaer, Masseria, and the OECD Health Equity Research Group Members 2004). Blendon and colleagues, for example, found that in Australia, Canada, New Zealand, and the UK, people with below-median incomes were less likely to report barriers to health care than people with below-median incomes in the United States. Furthermore, they found much smaller differences in the responses between people with above- and below-median incomes with regard to barriers in the UK than they found in the United States (Blendon et al. 2002: 185).

Similarly, we previously found that rates of both avoidable mortality (Weisz et al. 2007) and infant mortality (Rodwin and Neuberg 2005) were significantly higher among those living in the lowest-income neighborhoods of Manhattan than among people living in the rest of the borough. In contrast, we did not find a significant relationship between neighborhood of residence and rates of avoidable or infant mortality in Inner London and Paris.

At the same time, several studies suggest that access to specialty services (especially surgical care) is less equitable, even in health care systems with universal coverage. (See Roos and Mustard 1997; van Doorslaer et al. 2000; van Doorslaer, Koolman, and Puffer 2002; van Doorslaer, Masseria, and the OECD Health Equity Research Group Members 2004.) Julian Tudor Hart (1971) first referred to this pattern as the "inverse care law" - the fact that wealthy residents, despite their better health status, are more likely to receive specialty health services than poorer residents (Cissé, Luchini, and Moatti 2007; Hurst and Jee-Hughes 2001; Lu et al. 2007; Peacock, Devlin, and McGee 1999; Raine, Hutchings, and Black 2004; Schoen and Doty 2004; Wagstaff and van Doorslaer 1992; van Doorslaer and Wagstaff 1992; van Doorslaer et al. 2000; van Doorslaer et al. 2008). The purported distinction between access to primary and specialty care is illustrated by Roos and Mustard's study (1997), which concluded that the wealthier and healthier Winnipeg residents enjoy better access to specialty care. In Winnipeg, the system delivers "care according to socioeconomic characteristics that are strongly related to health sta- 
tus" (102). Residents of lower-income neighborhoods in Winnipeg receive more primary care and acute hospital admissions for medical conditions than residents of higher-income neighborhoods. In contrast, "specialists, particularly internists and surgical subspecialists, provide substantially more care to the healthiest group in Winnipeg, residents of the wealthiest neighborhoods, than to any other group in the city" (ibid.).

In our study, we examine how the English, French, and United States systems distribute access to health care. First, we assess the degree to which mortality and hospitalization varies by neighborhood income in Manhattan, Inner London, and Paris. Next, we compare how access to primary care and specialty procedures varies according to neighborhood income. It is useful to compare equity in access to health care among, as well as within, these three cities because they share many similar characteristics and provide notable advantages for more refined comparisons than what has been possible in much of the existing literature that focuses only on cross-national comparisons (Gusmano, Rodwin, and Weisz, forthcoming).

\section{Methods}

New York City (population 8 million), Greater London (7 million), and Paris and its first ring ( 6 million) are the largest cities among the higherincome nations of the OECD. We focus on their "urban cores"-Manhattan (1.5 million population), Inner London (2.7 million), and Paris (2.1 million) - which share a number of convergent characteristics. They are medical capitals with a disproportionate share of hospitals and specialist physicians. They are destinations for large immigrant communities from around the world, and in all three cities the arrival of recent immigrants has exacerbated social and spatial inequalities.

As we discuss below, the urban cores of these cities combine a mix of high- and low-income populations. The geographic distribution of income within these urban cores has remained remarkably consistent over time. For example, poverty has been concentrated in the East End and inner south boroughs of Inner London since the mid-nineteenth century (Hamnett 2003). Likewise, poverty in Paris has been concentrated in the northeast and in Manhattan, in Harlem and the Lower East Side.

The health status of residents in these three world cities appears to be the same or better, on average, than the health status of those living in their respective nations as a whole. Indeed, older persons in Paris and New York live longer than their counterparts who live elsewhere in these 
countries (Rodwin and Gusmano 2006). Of the three, New York has the highest infant mortality rate and lowest life expectancy at birth and at sixty-five, while the infant mortality rate is lowest and life expectancy is highest in Paris (Rodwin and Gusmano 2006; Rodwin and Neuberg 2005).

\section{Income Quartiles}

For residents of Manhattan and Paris, we used a comparable measure of median household income. Since household income data are not available in the UK, for Inner London we used the deprivation index in place of a direct income measure. Using income and the deprivation index as explanatory variables in the model would make London and the other two cities difficult to compare. As in our previous analyses of infant mortality (Rodwin and Neuberg 2005) and avoidable mortality (Weisz et al. 2007), we used income and the deprivation index to define an indicator variable. ${ }^{1}$

\section{Health Status Indicators}

We present age-adjusted rates of total mortality among residents of each city by neighborhood of residence. In addition, based on Roos and Mustard's (1997: 91) claim that premature death is "one of the most valid single indicators of health status capturing a population's need for health care," we present rates of mortality up to the age of seventy-four. Finally, we present age-adjusted mortality rates due to ischemic heart disease, diabetes, and breast cancer.

In addition to mortality rates, we present age-adjusted rates of total hospitalization as an indicator of morbidity. Finally, we present age-adjusted rates of hospitalization for three "low-variation" or "marker" conditions (Rodwin and Gusmano 2006; Wennberg 1987): acute myocardial infarction (AMI), hip fractures, and intestinal obstruction. These are conditions that are less affected by the extent to which the health care system provides access to primary care and for which the need for inpatient hospital-

1. For Manhattan and Paris, we let income $=1$ if a neighborhood was in the lowest-income quartile ( 3 in Manhattan; 5 in Paris). For London we let income $=1$ for each of the four boroughs in the highest-deprivation quartile. For all other neighborhoods, we let income $=0$. If the deprivation index in London captures the four lowest-income neighborhoods in the mostdeprived quartile, our combination of income and deprivation indicators select the lowestincome quartile neighborhoods for the three urban cores. 
ization is not in dispute. As the name "low variation" suggests, previous research has found that hospitalization rates for these conditions do not vary greatly across populations.

\section{Indicator of Access to Primary Care: Avoidable Hospital Conditions}

The hospital discharge rate for avoidable hospital conditions (AHC) is considered a valid measure of access to timely and effective primary care (Millman 1993). ${ }^{2}$ Primary care reduces the probability of hospitalization for diagnoses treated effectively outside the hospital setting - before flare-ups require hospital admission (Parchman and Culler 1994; Billings, Anderson, and Newman 1996). Such conditions include pneumonia, congestive heart failure, diabetes, and asthma. Although some studies question whether AHC can reliably distinguish health system characteristics from the socioeconomic status (SES) of health system populations (Blustein, Hanson, and Shea 1998), there is agreement that in the United States differences in rates of AHC among neighborhoods reflect disparities in access to primary care, not population health status (Oster and Bindman 2003; Wennberg 1987). As we discuss below, our findings support the notion that neighborhood-level differences in rates of AHC are not explained by differences in population health status in the Manhattan rates, but population health may explain neighborhood variations in these rates in our other cities.

\section{Surgical Procedure Indicators}

In contrast to rates of $\mathrm{AHC}$, we examine age-adjusted rates of a few referral-sensitive procedures. These are procedures that require referral to a specialist and are indicated for conditions that may not be immediately life threatening. We examine lower-extremity joint-replacement surgery and noncosmetic breast reconstruction surgery for women treated for breast

2. Weissman's original definition of AHC relies on ICD-9 (Weissman, Gatsonis, and Epstein 1992). Of the twelve conditions included, ten translate directly to ICD-10. Only two, neither of which are large contributors to the rate of $\mathrm{AHC}$, pyelonephritis and gangrene, require interpretation. To capture pyelonephritis (ICD-9 590.0, .1, and .8), we use codes ICD-10 N10-12, 13.6, and 15, which include pyelonephritits and acute and chronic tubulo-interstitial nephritis and pyonephrosis. To capture all cases of gangrene included in ICD-9 785.4, we use R0.2 (gangrene unspecified), supplemented with I73.9 (unspecified peripheral vascular disease) and I74.3 (embolus and thrombosis of arteries of the lower extremity). These minor differences in coding have a negligible impact. 
cancer, as well as hospital discharges for coronary revascularization percutaneous transluminal coronary angioplasty (PTCA) and coronary artery bypass graft surgery (CABG).

\section{Statistical Methods}

To test whether there is a statistically significant linear trend in mortality and hospitalization rates by income quartile of neighborhood, we use a chi-square test for trend with one degree of freedom. If health status is positively correlated with income quartile of neighborhood, then mortality and hospitalization rates will decrease as we move from the poorest to the highest-income neighborhoods.

\section{Health Status by Neighborhood}

\section{Characteristics of Residents by Income Quartile of Neighborhood}

Whether measured in terms of income, deprivation, or educational status, neighborhood disparities in socioeconomic status are large in all three cities but greatest in Manhattan (table 1). In Manhattan, household incomes range from $\$ 73,816$ on the Upper East Side to \$20,111 in Central Harlem. In contrast, the range in Paris is from $€ 36,161$ in the sixteenth to $€ 20,061$ in the eighteenth arrondissement. In Great Britain, household income data are not available, but variations in measures of social deprivation vary widely. For example, among the boroughs of Inner London, the percentage of persons who are "income deprived" ranges from 16.8 percent in Kensington to 58.26 percent in Tower Hamlets. Tower Hamlets' rank among all 354 local authorities in England is 16, while Kensington's is $177 .{ }^{3}$

Rates of total and premature mortality are higher among residents of poorer neighborhoods in all three cities (table 2). Residents of poorer neighborhoods in Inner London and Manhattan also suffer from higher mortality rates due to ischemic heart disease. The neighborhood-level differences in death rates due to diabetes are only significant in Manhattanwhere they are large. As Ross and Mustard (1997) found in Winnipeg, death rates due to breast cancer do not vary significantly by neighborhood in any of these cities.

3. The derivation of the deprivation index is available at the following address: www .communities.gov.uk/archived/general-content/communities/indicesofdeprivation/216309/ (accessed March 20, 2009). 
Table 1 Socioeconomic Status: Manhattan, Inner London, Paris

\begin{tabular}{|c|c|c|c|c|c|}
\hline & $\begin{array}{c}\text { Total } \\
\text { Population }\end{array}$ & $\%$ Female & 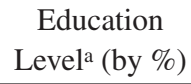 & $\begin{array}{l}\text { Median Household } \\
\text { Income Range }\end{array}$ & $\begin{array}{c}\text { Deprivation } \\
\text { Score }\end{array}$ \\
\hline \multicolumn{6}{|c|}{ Manhattan } \\
\hline Q1 & 529,882 & 52.86 & 17.00 & $\$ 20,111-\$ 27,693$ & N/A \\
\hline Q2 & 320,135 & 50.25 & 48.14 & $\$ 41,335-\$ 54,051$ & N/A \\
\hline Q3 & 304,415 & 52.08 & 64.16 & $\$ 57,597-\$ 65,038$ & N/A \\
\hline Q4 & 371,749 & 54.36 & 71.09 & $\$ 68,355-\$ 73,816$ & N/A \\
\hline \multicolumn{6}{|l|}{ Paris } \\
\hline Q1 & 778,982 & 51.90 & 21.71 & $€ 20,061-€ 22,470$ & N/A \\
\hline Q2 & 417,795 & 52.83 & 28.68 & $€ 22,575-€ 25,971$ & N/A \\
\hline Q3 & 566,629 & 54.24 & 23.80 & $€ 26,506-€ 28,551$ & N/A \\
\hline Q4 & 361,840 & 54.34 & 40.22 & $€ 28,572-€ 36,161$ & N/A \\
\hline \multicolumn{6}{|c|}{ Inner London } \\
\hline Q1 & 642,821 & 50.99 & 28.23 & N/A & 58.26 \\
\hline Q2 & 903,339 & 51.42 & 38.38 & N/A & 42.60 \\
\hline Q3 & 612,184 & 51.91 & 39.19 & N/A & 34.97 \\
\hline Q4 & 607,770 & 51.90 & 47.50 & N/A & 21.02 \\
\hline
\end{tabular}

Sources: U.S. Census 2000; French Census 1999; UK Office of National Statistics 2001 aBachelor's degree to higher

The rate of total hospitalization is higher among residents of poorer neighborhoods in all three cities (table 3). Hospitalization rates for our three "low-variation" or "marker" conditions are also consistent with our mortality findings. Rates of AMI are higher among residents of poorer neighborhoods in Inner London and Manhattan, which is consistent with the results for ischemic heart disease mortality. In contrast, rates of AMI do not vary greatly among the neighborhoods of Paris. As we expected, there is little variation in rates of hip fracture and intestinal obstruction across neighborhoods of these cities.

\section{Access to Primary Care}

Access to primary care, as measured by AHC, indicates that residents of lower-income neighborhoods are hospitalized with these conditions at a higher rate than residents of higher-income neighborhoods in all three cities, but both the overall rate of AHC and the neighborhood disparities are greatest in Manhattan (table 4). Indeed, the age-adjusted rate of AHC in 
Table 2 Health Status by Income Quartile of Neighborhood: Mortality

\begin{tabular}{|c|c|c|c|c|c|}
\hline & $\begin{array}{l}\text { Age- } \\
\text { Adjusted } \\
\text { Total } \\
\text { Mortality } \\
\text { Rate }\end{array}$ & $\begin{array}{l}\text { Age- } \\
\text { Adjusted } \\
\text { Premature } \\
\text { Mortality } \\
\text { Rate }\end{array}$ & $\begin{array}{c}\text { Age-Ischemic } \\
\text { Heart } \\
\text { Disease } \\
\text { Mortality } \\
\text { Rate }\end{array}$ & $\begin{array}{c}\text { Age- } \\
\text { Adjusted } \\
\text { Diabetes } \\
\text { Mortality } \\
\text { Rate }\end{array}$ & $\begin{array}{c}\text { Age- } \\
\text { Adjusted } \\
\text { Breast Cancer } \\
\text { Mortality } \\
\text { Rate }\end{array}$ \\
\hline \multicolumn{6}{|l|}{ Manhattan } \\
\hline Q1 & 858 & 449 & 180 & 32 & 16 \\
\hline Q2 & 721 & 330 & 101 & 16 & 13 \\
\hline Q3 & 654 & 253 & 152 & 12 & 15 \\
\hline Q4 & $581 * * *$ & $210 * * *$ & $134 * * *$ & $8 * * *$ & 17 \\
\hline Ratio: Q1:Q4 & 1.48 & 2.14 & 1.34 & 4.01 & 0.97 \\
\hline \multicolumn{6}{|l|}{ Paris } \\
\hline Q1 & 960 & 280 & 34 & 5 & 13 \\
\hline Q2 & 985 & 285 & 46 & 6 & 19 \\
\hline Q3 & 641 & 170 & 22 & 3 & 12 \\
\hline Q4 & $482 * * *$ & $95^{* * * *}$ & 36 & 4 & 19 \\
\hline Ratio: Q1:Q4 & 1.99 & 2.94 & 0.94 & 1.37 & 0.71 \\
\hline \multicolumn{6}{|l|}{ Inner London } \\
\hline Q1 & 932 & 427 & 181 & 16 & 18 \\
\hline Q2 & 899 & 401 & 139 & 12 & 18 \\
\hline Q3 & 868 & 374 & 132 & 9 & 20 \\
\hline Q4 & $792 * *$ & $314 * * *$ & $111 * * *$ & 9 & 17 \\
\hline Ratio: Q1:Q4 & 1.18 & 1.36 & 1.62 & 1.81 & 1.07 \\
\hline
\end{tabular}

Sources: Manhattan - Bureau of Vital Statistics of the New York City Department of Health and Mental Hygiene, 1999-2003; Paris - Institut National de la Santé et de la Recherche Médicale (INSERM), 1995-1999; Inner London — United Kingdom Office of National Statistics, 2001-2003

**Significant at the .01 level; ***significant at the .001 level

the poorest neighborhoods of Manhattan (East Harlem, Central Harlem, and Washington Heights) is more than double the rate of AHC in the poorest neighborhoods of Paris and nearly double the rate in the most-deprived neighborhoods of Inner London.

Although these results suggest a degree of horizontal inequity in access to primary care in all three cities, it is important to note that disparities in the rates of AHC among neighborhoods in Inner London and Paris are consistent with disparities in health status, as measured by total and premature mortality and total hospitalization. Thus, neighborhood-level differences in AHC in Inner London and Paris may be due to differences in 
Table 3 Health Status by Income Quartile of Neighborhood: Hospital Discharges per 100,000

\begin{tabular}{|c|c|c|c|c|}
\hline & $\begin{array}{l}\text { Age-Adjusted } \\
\text { Hospital } \\
\text { Discharges } \\
\text { (Total) }\end{array}$ & $\begin{array}{l}\text { Age-Adjusted } \\
\text { Acute } \\
\text { Myocardial } \\
\text { Infarction (AMI) }\end{array}$ & $\begin{array}{c}\text { Age-Adjusted } \\
\text { Hip } \\
\text { Fracture }\end{array}$ & $\begin{array}{c}\text { Age-Adjusted } \\
\text { Intestinal } \\
\text { Obstruction }\end{array}$ \\
\hline \multicolumn{5}{|l|}{ Manhattan } \\
\hline Q1 & 16,921 & 156 & 43 & 75 \\
\hline Q2 & 12,822 & 148 & 63 & 75 \\
\hline Q3 & 9,533 & 111 & 61 & 60 \\
\hline Q4 & $9,859 * * *$ & $99 * * *$ & 70 & 78 \\
\hline Ratio: Q1:Q4 & 1.72 & 1.57 & 0.61 & 0.97 \\
\hline \multicolumn{5}{|l|}{ Paris } \\
\hline Q1 & 16,803 & 86 & 100 & 100 \\
\hline Q2 & 15,015 & 78 & 92 & 92 \\
\hline Q3 & 14,009 & 66 & 91 & 91 \\
\hline Q4 & $12,556^{* * *}$ & 60 & 83 & $62 *$ \\
\hline Ratio: Q1:Q4 & 1.34 & 1.42 & 1.21 & 1.62 \\
\hline \multicolumn{5}{|l|}{ Inner London } \\
\hline Q1 & 14,961 & 192 & 115 & 44 \\
\hline Q2 & 13,236 & 121 & 102 & 42 \\
\hline Q3 & 12,382 & 138 & 104 & 41 \\
\hline Q4 & $12,094 * * *$ & $132 * * *$ & 114 & 37 \\
\hline Ratio: Q1:Q4 & 1.24 & 1.45 & 1.01 & 1.21 \\
\hline
\end{tabular}

Sources: Manhattan - Statewide Planning and Research Cooperative System (SPARCS), 1999-2002; Paris — French Ministry of Health's Hospital Reporting System: Programme pour la Médicalisation des Systèmes d'Information (PMSI), 1999-2001; Inner London — UK Department of Health Hospital Episode Statistics (HES), 1999-2003

*Significant at the .05 level; ***significant at the .001 level

population health, not access to primary care. This claim is supported by our previous analysis of $\mathrm{AHC}$ in Paris. When we ran a logistic regression to predict rates of AHC among adults (i.e., those over eighteen years old) in Paris, we found no relationship between neighborhood of residence and AHC after controlling for age, gender, and morbidity (Gusmano, Rodwin, and Weisz 2006).

In Manhattan, however, neighborhood disparities in AHC are much larger than disparities in health status. The ratio of the age-adjusted rate of AHC in the poorest to richest neighborhoods is 2.78, compared with a ratio of 1.48 for age-adjusted total mortality, 2.14 for age-adjusted premature mortality, and 1.72 for age-adjusted total hospitalization. This is con- 
Table 4 Access to Primary Care by Income Quartile of Neighborhood

\begin{tabular}{cc}
\hline \multicolumn{1}{c}{ Avoidable Hospital Conditions per 100,000 } \\
\hline Manhattan & $1,995.12$ \\
Q1 & $1,222.22$ \\
Q2 & 847.96 \\
Q3 & $718.76^{* * * *}$ \\
Q4 & 2.78 \\
Ratio: Q1:Q4 & \\
& \\
Paris & 936.73 \\
Q1 & 742.14 \\
Q2 & 650.13 \\
Q3 & $531.45^{* * *}$ \\
Q4 & 1.76 \\
Ratio: Q1:Q4 & \\
Inner London & \\
Q1 & $1,108.45$ \\
Q2 & 870.12 \\
Q3 & 870.35 \\
Q4 & $840.33^{* * * *}$ \\
Ratio: Q1:Q4 & 1.32 \\
\hline
\end{tabular}

Sources: Manhattan - Statewide Planning and Research Cooperative System (SPARCS), 1999-2002; Paris — French Ministry of Health's Hospital Reporting System: Programme pour la Médicalisation des Systèmes d'Information (PMSI), 1999-2001; Inner London - UK Department of Health Hospital Episode Statistics (HES), 1999-2003

$* * *$ Significant at the .001 level

sistent with previous studies of access to care in Manhattan, which find large neighborhood disparities in access to care that cannot be explained by differences in need (Billings et al. 1993; Gusmano, Rodwin, and Weisz 2006).

\section{Access to Specialty Care}

In Manhattan, residents of richer neighborhoods receive revascularization procedures, lower-joint replacements, and noncosmetic breast reconstruction at much higher rates than residents of poorer neighborhoods (table 5). The differences for breast reconstruction are particularly striking. Despite the fact that age-adjusted breast cancer mortality rates do not vary by neighborhood, residents of the richest neighborhoods in Manhattan receive breast reconstruction at a rate that is more than two-and-a-half times higher than the rate in the poorest neighborhoods. The rate of revascular- 
Table 5 Access to Specialty Care by Income Quartile of Neighborhood

\begin{tabular}{cccc}
\hline & $\begin{array}{c}\text { Age-Adjusted } \\
\text { Discharge Rate for } \\
\text { Revascularizations } \\
\text { per 100,000 (35+) }\end{array}$ & $\begin{array}{c}\text { Age-Adjusted } \\
\text { Lower-Joint } \\
\text { Replacement Rate }\end{array}$ & $\begin{array}{c}\text { Age-Adjusted } \\
\text { Breast }\end{array}$ \\
Reconstruction Rate \\
\hline Manhattan & & & \\
Q1 & 212.77 & 121.03 & 18.37 \\
Q2 & 246.71 & 127.12 & 25.29 \\
Q3 & 231.55 & 143.33 & 37.59 \\
Q4 & 261.01 & $171.33^{*}$ & $50.46^{* * *}$ \\
Q1:Q4 & 0.82 & 0.71 & 0.36 \\
& & & \\
Paris & & & 28.29 \\
Q1 & 157.54 & 91.16 & 30.07 \\
Q2 & 161.47 & 89.41 & 35.80 \\
Q3 & 148.96 & 79.97 & 36.97 \\
Q4 & 169.05 & 74.61 & 0.77 \\
Q1:Q4 & 1.07 & 1.22 & \\
Inner London & & & 24.85 \\
Q1 & 108.33 & 133.41 & 19.42 \\
Q2 & 110.28 & 142.40 & 35.70 \\
Q3 & 123.46 & 142.46 & 30.78 \\
Q4 & $147.80^{*}$ & 138.76 & 0.81 \\
Q1:Q4 & 0.73 & 0.96 & \\
\hline
\end{tabular}

Sources: Manhattan - Statewide Planning and Research Cooperative System (SPARCS), 1999-2002; Paris - French Ministry of Health's Hospital Reporting System: Programme pour la Médicalisation des Systèmes d'Information (PMSI), 1999-2001; Inner London — UK Department of Health Hospital Episode Statistics (HES), 1999-2003

*Significant at the .05 level; **significant at the .01 level; ***significant at the .001 level

ization is also significantly higher in the least deprived neighborhoods of Inner London, despite the fact that the rate of heart disease - measured in terms of mortality or hospitalization - is significantly higher among residents of more-deprived neighborhoods. In Paris, access for these procedures does not vary significantly by neighborhood (table 5 ).

\section{Summary and Policy Implications}

We find strong evidence of horizontal equity in the use of primary and acute hospital care in Inner London, but the evidence is mixed with regard to surgical care. Lower-joint replacements and noncosmetic breast recon- 
struction appear to be equitably distributed within Inner London, but residents of wealthier neighborhoods receive more revascularizations than do residents of poorer neighborhoods despite significantly lower rates of heart disease in these neighborhoods. Nevertheless, the extent of horizontal inequity in access to specialty services is not as great in Inner London as in Manhattan. In contrast to Manhattan and Inner London, Paris comes closest to achieving horizontal equity in the use of both primary and specialty health care services. Manhattan, however, presents the most striking contrast in comparison to both Inner London and Paris.

In Manhattan, we find much larger gaps in access by neighborhood income than in the other urban cores. Some of this is due to the more significant geographic concentration of poverty (and lower rates of insurance coverage) in Manhattan. Race-based residential segregation and the geographic concentration of poverty among blacks in Manhattan contribute to disparities in population health as well as in access to health care (Schulz et al. 2002; Weisz and Gusmano 2006). Our previous analyses of AHC and the treatment of heart disease provide evidence that insurance coverage, gender, and race all represent significant barriers to the use of primary and specialty care services (Gusmano, Rodwin, and Weisz 2006; Gusmano et al. 2007). The odds of a Manhattan resident without health insurance being hospitalized with an AHC are more than 80 percent higher than they are for a privately insured resident (Gusmano, Rodwin, and Weisz 2006). The odds of an uninsured resident hospitalized with heart disease receiving a revascularization are more than 60 percent lower than they are for a privately insured resident hospitalized with the same diagnosis (Gusmano et al. 2007).

These findings suggest that universal insurance coverage, alone, is not sufficient to eliminate geographic inequities in access to care. Nevertheless, they also indicate that universal coverage can reduce noted disparities in access to primary care by reducing financial barriers to health care. Finally, our analysis also casts doubt on the notion that the number of payers in a health care system with universal coverage affects its capacity to achieve horizontal equity. Access to care, particularly primary care, is more equitable in Inner London than in Manhattan, but the goal of equal treatment for equal need has been realized most completely in Paris, whose residents are covered by a multiple-payer system. The geographic distribution of health care resources and financial barriers to care - more than the number of payers - are all more likely to influence the extent to which a health care system achieves horizontal equity in the use of health services. 
As U.S. reformers have studied systems of universal health care coverage abroad and led campaigns to extend health insurance coverage at home, their opponents have denounced their proposed reforms as worrisome steps toward increasing government control that would lead to "socialized medicine" (Starr 1985). Likewise, advocates for a "single payer" are attacked by their opponents as supporting "government-run" health care systems that resemble the worst caricatures of a national health service - one with severe limits on health care spending resulting in waiting lists and other obstacles to health care access. The comparison of access to specialty services we present above suggests a more complex story.

Residents of Inner London do receive far fewer revascularizations than do residents of Manhattan or Paris, but age-adjusted rates of lower-joint replacement and breast reconstruction are lower only among residents of the highest income neighborhoods of Inner London. For all other residents, the age-adjusted rates of these procedures are remarkably similar to the other urban cores. Furthermore, the comparison with Paris implies that the cost of horizontal equity in access to health care services need not be poor access to specialty care services. Age-adjusted rates of revascularization, lower-joint replacement, and breast reconstruction in Paris relative to the health needs of the population — are at least as high as they are in Manhattan. By spending a much larger percentage of its GDP on health care than the British (and most other countries in Europe), the French are able to provide equitable access to primary care while maintaining high levels of access to specialty services. In the context of American debates on health care reform, we must recognize the diversity of health system models with universal coverage and develop more sophisticated methods for assessing and extending the specific dimensions of health care access on which we have shed light in this article.

\section{References}

Billings, J., G. M. Anderson, L. S. Newman. 1996. Recent Findings on Preventable Hospitalizations. Health Affairs 15 (3): 239-249.

Billings, J., L. Zeitel, J. Lukomnik, T. S. Carey, A. E. Blank, and L. Newman. 1993. Impact of Socioeconomic Status on Hospital Use in New York City. Health Affairs 12 (1): $162-173$.

Blendon, R. J., C. Schoen, C. M. DesRoches, R. Osborn, K. L. Scoles, and K. Zapert. 
2002. Inequities in Health Care: A Five-Country Survey. Health Affairs 21 (3): $182-191$.

Blustein, J., K. Hanson, and S. Shea. 1998. Preventable Hospitalizations and Socioeconomic Status. Health Affairs 17 (2): 177-189.

Bureau of Vital Statistics of the New York City Department of Health and Mental Hygiene, 1999-2003.

Cissé, B., S. Luchini, and J. P. Moatti. 2007. Progressivity and Horizontal Equity in Health Care Finance and Delivery: What about Africa? Health Policy 80:51-68.

French Bureau of the Census. 1999. Census of the Population.

French Ministry of Health's Hospital Reporting System: Programme pour la Médicalisation des Systèmes d'Information (PMSI), 1999-2001.

Gusmano, M. K., V. G. Rodwin, and D. Weisz. 2006. A New Way to Compare Health Systems: Avoidable Hospital Conditions in Manhattan and Paris. Health Affairs 25:510-520.

- Forthcoming. A New Way to Compare Health Systems: Access to Care in New York, London, and Paris. Baltimore: Johns Hopkins University Press.

Gusmano, M. K., V. G. Rodwin, D. Weisz, and D. Das. 2007. A New Approach to the Comparative Analysis of Health Systems: Invasive Treatment for Heart Disease in the U.S., France, and Their Two World Cities. Health Economics, Policy, and Law 2:73-92.

Hamnett, C. 2003. Unequal City: London in the Global Arena. London: Routledge.

Hurst, J., and M. Jee-Hughes. 2001. Performance Measurement and Performance Management in OECD Health Systems. Labour Market and Social Policy Occasional Papers No. 47. Paris: OECD.

Institut National de la Santé et de la Recherche Médicale (INSERM), 1995-1999.

Lu, J-f. R., G. M. Leung, S. Kwon, K. Y. K. Tin, E. van Doorslaer, and O. O’Donnell. 2007. Horizontal Equity in Health Care Utilization Evidence from Three HighIncome Asian Economies. Social Science and Medicine 64:199-212.

Macinko, J., B. Starfield, and L. Shi. 2003. The Contribution of Primary Care Systems to Health Outcomes within Organisation for Economic Cooperation and Development (OECD) Countries, 1970-1998. Health Services Research 38:831-865.

Millman, M., ed. 1993. Access to Health Care in America. Committee on Monitoring Access to Personal Health Care Services, Institute of Medicine. Washington, DC: National Academy Press.

Oliver, A. J. 2008. Unpublished manuscript. Reflections on the Development of UK Health Inequalities Policy. London School of Economic and Political Science.

Oster, A., and A. B. Bindman. 2003. Emergency Department Visits for Ambulatory Care Sensitive Conditions: Insights into Preventable Hospitalizations. Medical Care 41:198-207.

Parchman, M. L., and S. Culler. 1994. Primary Care Physicians and Avoidable Hospitalizations. Journal of Family Practice 39 (2): 123-128.

Peacock, D., N. Devlin, and R. McGee. 1999. The Horizontal Equity of Health Care in New Zealand. Australian and New Zealand Journal of Public Health 23 (2): $126-130$.

Raine, R., A. Hutchings, and N. Black. 2004. Is Publicly Funded Health Care Really 
Distributed According to Need? The Example of Cardiac Rehabilitation in the UK. Health Policy 67:227-235.

Rodwin, V. G., and M. K. Gusmano, eds. 2006. Growing Older in World Cities: New York, London, Paris, and Tokyo. Nashville, TN: Vanderbilt University Press.

Rodwin, V., and L. Neuberg. 2005. Infant Mortality and Income in Four World Cities: New York, London, Paris, and Tokyo. American Journal of Public Health 95:86-90.

Roos, N. P., and C. Mustard. 1997. Variation in Health and Health Care Use by Socioeconomic Status in Winnipeg, Canada: Does the System Work Well? Yes and No. Milbank Quarterly 75:89-111.

Schoen, C., and M. M. Doty. 2004. Inequities in Access to Medical Care in Five Countries: Findings from the 2001 Commonwealth Fund International Health Policy Survey. Health Policy 67:309-322.

Schulz, A. J., D. R. Williams, B. A. Israel, L. B. Lempert. 2002. Racial and Spatial Relations as Fundamental Determinants of Health in Detroit. Milbank Quarterly 80:677-705.

Starr, P. 1985. The Social Transformation of American Medicine. New York: Basic Books.

Statewide Planning and Research Cooperative System (SPARCS), 1999-2002.

Tudor Hart, J. 1971. The Inverse Care Law. Lancet 328:404-412.

United Kingdom. Department of Health. 1999-2003. Hospital Episode Statistics (HES).

United Kingdom. Office of National Statistics. 2001-2003. UK Census of the Population.

United States Census Bureau. 2000. United States Census. Washington, DC: U.S. Census Bureau.

van Doorslaer, E., P. Clarke, E. Savage, and J. Hall. 2008. Horizontal Inequities in Australia's Mixed Public/Private Health Care System. Health Policy 86:97-108.

van Doorslaer, E., X. Koolman, and F. Puffer. 2002. Equity in the use of physician visits in OECD countries: Has equal treatment for equal need been achieved? In Measuring Up: Improving Health Systems Performance in OECD Countries, ed. OECD, 225-248. Paris: OECD.

van Doorslaer, E., C. Masseria, and the OECD Health Equity Research Group Members. 2004. Income-related Inequality in the Use of Medical Care in Twenty-one OECD Countries. OECD Working Paper No. 14. Paris: Organisation for Economic Co-operation and Development.

van Doorslaer, E., and A. Wagstaff. 1992. Equity in the Delivery of Health Care: Some International Comparisons. Journal of Health Economics 11:389-411.

van Doorslaer, E, A. Wagstaff, H. van der Burg, T. Christiansen, D. De Graeve, I. Duchesne, U.-G. Gerdtham, et al. 2000. Equity in the Delivery of Health Care in Europe and the U.S. Journal of Health Economics 19:553-583.

Wagstaff, A., and E. van Doorslaer. 1992. Equity in the Finance of Health Care: Some International Comparisons. Journal of Health Economics 11:361 -387.

Weissman, J. S., C. Gatsonis, and A. M. Epstein. 1992. Rates of Avoidable Hospitalization by Insurance Status in Massachusetts and Maryland. Journal of the American Medical Association 268:2388-2394. 
Weisz, D., and M. K. Gusmano. 2006. The Health of Older New Yorkers. In Growing Older in World Cities: New York, London, Paris, and Tokyo, ed. V. Rodwin and M. Gusmano, 58-77. Nashville, TN: Vanderbilt University Press.

Weisz, D., M. K. Gusmano, V. G. Rodwin, and L. Neuberg. 2007. Population Health and the Health System: Avoidable Mortality in Three Wealthy Nations and Their World Cities. European Journal of Public Health 18 (2): 166-172.

Wennberg, J. 1987. Population Illness Rates Do Not Explain Population Hospitalization Rates. Medical Care 25:354-359. 
